\title{
Investigation of the cardiovascular risk profile in a south Brazilian city: surveys from 2012 to 2016
} Investigação do perfil de risco cardiovascular em uma cidade no sul do Brasil: inquéritos de 2012 a 2016

\author{
Jamir Pitton Rissardo', Ana Letícia Fornari Caprara', Ana Lucia Cervi Prado², Martim Tobias Bravo Leite
}

\begin{abstract}
The aim of this study was to investigate the cardiovascular risk profile of the participants recruited from stroke awareness campaigns in Santa Maria RS, Brazil, from 2012 to 2016, using the simplified version of the Framingham Risk Score (FRS). Questionnaires were used to evaluate 1,061 participants from 20 to 74 years old. Data on cardiovascular risk factors were obtained. The prevalence of risk factors and mean FRS for men and women were estimated. The FRS for women was $11.8 \%$ (moderate risk) and $24.7 \%$ for men (high risk). The vascular age for women was 61.6 years, whereas the vascular age for men was 66 years. Two percent of women had hypertension and diabetes, while both these risk factors were present in $5 \%$ of men. Based on the data, the prevalence of stroke risk factors is worrisome, as are the numbers of individuals with moderate and high cardiovascular risk in Santa Maria.
\end{abstract}

Keywords: risk factors; stroke; cardiovascular diseases.

\section{RESUMO}

O objetivo desse estudo foi investigar o perfil de risco cardiovascular dos participantes de campanhas sobre acidente vascular cerebral (AVC) em Santa Maria-RS, dos anos de 2012 a 2016, por meio do Escore de Risco de Framingham (ERF) simplificado. Foram utilizados questionários para avaliação de 1061 indivíduos de 20 a 74 anos. Informações sobre fatores de risco cardiovascular foram obtidas. 0 ERF médio para as mulheres foi de 11,8\% (risco moderado) e para os homens, $24,7 \%$ (risco alto). A idade vascular média no sexo feminino foi de 61,6 anos, sendo 66 anos o valor encontrado para o sexo masculino. $2 \%$ das mulheres eram hipertensas e tabagistas; nos homens, a concomitância desses fatores de risco foi de $5 \%$. Assim, as prevalências de fatores de risco para AVC e de indivíduos com moderado e alto risco cardiovascular são alarmantes em Santa Maria.

Palavras-chave: fatores de risco; acidente vascular cerebral; doenças cardiovasculares.

Stroke is the third leading cause of disability, and the second most common cause of mortality in the world ${ }^{1}$. Among Latin American countries, Brazil has the highest mortality rates due to stroke ${ }^{2}$.

However, epidemiological studies on stroke are still scarce in many Brazilian regions. In the case of the city of Santa Maria, Rio Grande do Sul, it is possible that the prevalence of risk factors is different from that observed in other regions of the country, considering local traditions, such as the high consumption of foods rich in saturated fats and sodium, as well as increased rates of smoking and hypertension in Rio Grande do Sul, compared to other states in the country,4.

In this context, one of the benefits of conducting surveys in low and middle-income countries like Brazil is the opportunity of producing data based on large samples through relatively inexpensive methods, which could be representative of a population and therefore useful for management of resources in public health.

Gaziano et al. ${ }^{5}$ developed calculations that were able to predict cardiovascular outcomes as effectively as methods that use laboratory tests. D'Agostino et al. ${ }^{6}$ used sex-specific simplified risk prediction models based on non-laboratory measures. They also formulated the concept of "vascular age", which is the vascular age of an individual calculated as the age of a person with the same cardiovascular risk, but with all the other risk factors within the limits of normality 6

Based on these assumptions, this study aimed to investigate the cardiovascular risk profile of men and women who participated in stroke awareness campaigns in Santa

${ }^{1}$ Universidade Federal de Santa Maria, Santa Maria RS, Brasil;

${ }^{2}$ Universidade Federal de Santa Maria, Departamento de Fisioterapia, Santa Maria RS, Brasil.

Correspondence: Jamir Pitton Rissardo; Universidade Federal de Santa Maria Centro de Ciências da Saúde - Prédio 26 A; Faixa de Camobi, Km 09; $97105-900$; Santa Maria RS, Brasil; E-mail: jamirrissardo@gmail.com

Conflict of interest: There is no conflict of interest to declare.

Received 08 June 2017, Received in final form 27 December 2017, Accepted 27 January 2018. 
Maria from the year 2012 to 2016, using a predictive model of risk based on non-laboratory measures derived from the Framingham Study and to compare these results with those from other similar studies, to verify whether local traditions produced any effect on the overall prevalence of cardiovascular risk factors in this particular population. It also aimed to quantify the same risk in the form of "vascular age" and to identify the most prevalent individual and combined cardiovascular risk factors among these individuals.

\section{METHODS}

The data collection of the study was carried out through surveys obtained by convenience sampling, during stroke awareness campaigns organized by professionals and academics from the departments of Physical Therapy and Medicine, who were previously trained. These campaigns occurred between the years of 2012 and 2016, during one day in the second semester of each year. Passers-by who voluntarily attended the stroke awareness campaign site were invited to participate in the study. The inclusion criteria were age between 20 and 74 years and absence of stroke or previous cardiovascular diseases reported at the time of the questionnaire. All participants in the research signed an informed consent. This study fulfills the requirements of the Ethics Committee of the Federal University of Santa Maria.

The questionnaire applied for data collection contained: general identification items; questions regarding current treatment for systemic arterial hypertension and diabetes; personal history of cardiovascular diseases; current smoking status. Items referring to anthropometric measures (weight, height and waist circumference), capillary blood glucose values; systolic and diastolic blood pressure were obtained on the day of the study, and an evaluation form was filled in by health professionals and trained students.

For the anthropometric measurements, portable electronic scales and measuring tapes were used. Two blood pressure (BP) measurements were also performed through the indirect auscultatory technique with a calibrated sphygmomanometer. The measurements were spaced five minutes apart, and the last measurement was recorded on the evaluation form. Blood glucose was measured by a hemoglucotest.

Individuals were considered to be in treatment for hypertension if they reported the use of one or more antihypertensive agents. Hypertension was also classified as unknown or absent, based on the answers of the individuals in the study. Values $\geq 140 \mathrm{mmHg}$ for systolic blood pressure, and values $\geq$ $90 \mathrm{mmHg}$ for diastolic blood pressure were considered high ${ }^{7}$.

Regarding diabetes, only those individuals who reported the use of antidiabetic drugs in the previous two weeks were considered diabetic. Diabetes was also classified as unknown or absent based on each individual's response. Postprandial capillary glycemia after two hours > $140 \mathrm{mg} / \mathrm{dL}$ was considered elevated for non-diabetic individuals. In the case of diabetics, glycemic levels > $180 \mathrm{mg} / \mathrm{dL}$ were classified as poor glycemic control ${ }^{8}$.

For the definition of increased waist circumference, the reference values used were $\geq 88 \mathrm{~cm}$ for women and $\geq 102 \mathrm{~cm}$ for men. We defined a body mass index (BMI) $\geq 25 \mathrm{~kg} / \mathrm{m}^{2}$ as overweight; and a BMI $\geq 30 \mathrm{~kg} / \mathrm{m}$ as obese $\mathrm{e}^{2,9,10,11}$.

Individuals were considered sedentary when they reported not participating in any kind of physical activity at work, at home or at leisure, or when they reported participating in physical activities for periods shorter than 20 minutes a day and with frequencies less than three times per week ${ }^{12}$. Participants were classified as smokers if they currently smoked one or more cigarettes per day.

For the prediction of cardiovascular risk in 10 years, a simplified Framingham Risk Score (FRS) developed for use in primary care, which takes into account only non-laboratory measures, was applied ${ }^{13}$. These variables included age, BMI, systolic blood pressure, use of antihypertensive drugs, current smoking habit, and diabetes ${ }^{13}$. Cardiovascular risk is expressed as a percentage and estimates the probability of a cardiovascular event starting in the next 10 years.

The concept of "cardiac age/vascular age", created by D’Agostino et al. ${ }^{6}$ was also used, aiming to simplify the understanding of the cardiovascular risk, expressed in percentages. It is a distinct measurement used to assess the same risk, but in the form of "cardiac age/vascular age". According to the authors, the "vascular age" of an individual is calculated as the age of a person with the same estimated cardiovascular risk, but with all others risk factors at normal levels ${ }^{6}$.

The Epi Info ${ }^{\mathrm{m}}$, version 7.1 (CDC, Atlanta) was used to create a database. Double data entry and standardized procedures were performed for quality checking. The data were then transferred to the SPSS software version 23 for statistical analysis.

We used the statistical software $\mathrm{G}^{*}$ Power to perform post hoc power analyses and determine if our non-significant results were due to a lack of statistical power. This analysis indicated that a sample of 1,003 individuals would be enough to detect small size effects $(\mathrm{d}=0.2)$ with more than $90 \%$ power using a t-test between means and with alpha at 0.05 , two-tailed. As for chi-square, the same sample size would allow the detection of small effects $(\mathrm{d}=0.1)$ with $83 \%$ statistical power. Thus, the non-significant results were unlikely to be due to a small sample size ${ }^{14}$.

The FRS was codified into three categories: $<10 \%=$ low risk; $10-20 \%=$ moderate risk; $>20 \%=$ high risk. For further comparisons, data on the FRS and cardiac age/vascular age were divided into three age groups (20-39 years, 40-59 years, and $\geq 60$ years). Details about the calculations used for these estimates are available at the Framingham Study electronic address cited in the references of this article ${ }^{13}$.

The prevalence of risk factors was estimated for the total sample and stratified by sex. Continuous variables were 
represented by mean and standard deviation, and categorical variables were represented by proportions. In order to perform analyses between groups, chi-square tests were used for proportions and t-tests were used for means. Values of $\mathrm{p}<$ 0.05 were considered statistically significant.

\section{RESULTS}

In total, 1,061 participants aged 20 to 74 years were included in the analysis of the general characteristics. Due to missing data, only 1,003 of these 1,061 participants were included in the overall cardiovascular risk profile assessment. Table 1 shows the general characteristics of the participants and the prevalence of cardiovascular risk factors divided by sex.

In the subgroup analysis, of the 84 individuals who reported not knowing their state of hypertension, 21 (25\%) presented with levels of systolic blood pressure $\geq 140 \mathrm{mmHg}$ and diastolic blood pressure $\geq 90 \mathrm{mmHg}$. Throughout the study, 155 participants (14.6\%) reported receiving treatment for diabetes. Among the 126 participants who reported not knowing whether they were diabetic, seven had postprandial glycemic levels after two hours higher than $140 \mathrm{mg} / \mathrm{dL}$. Postprandial glycemia after two hours in the population, on average, was $109.2 \mathrm{mg} / \mathrm{dL}$.

Table 2 shows the 10-year cardiovascular risk profile according to the FRS, based on non-laboratory parameters and expressed in percentages, and the vascular age, expressed in years. There were significant differences between men and women in all of the measures shown in this table.

The Figure represents the prevalence of risk factors according to each risk category. About $58 \%(\mathrm{~N}=306)$ of the women and $60 \%(n=320)$ of the men presented with either diabetes, or hypertension, or were smokers. Approximately $4 \%(n=21)$ of men and the same percentage of women

Table 1. Baseline characteristics

\begin{tabular}{|c|c|c|c|c|}
\hline Variables & $\begin{array}{c}\text { Women } \\
(n=527,49.7 \%)\end{array}$ & $\begin{array}{c}\text { Men } \\
(n=534,50.3 \%)\end{array}$ & $\begin{array}{c}\text { Total } \\
(\mathrm{n}=1061,100 \%)\end{array}$ & $\mathrm{p}$-value \\
\hline Age, mean (SD), years & $54.7(15.3)$ & $57.1(14.3)$ & $55.9(14.8)$ & \multirow{4}{*}{$0.008^{*}$} \\
\hline $20-39, n,(\%)$ & $85(8.0)$ & $61(5.7)$ & $146(13.8)$ & \\
\hline $40-59, n,(\%)$ & $226(21.3)$ & $217(20.4)$ & $443(41.7)$ & \\
\hline$\geq 60, n,(\%)$ & $216(20.4)$ & $256(24.1)$ & $472(44.5)$ & \\
\hline $\mathrm{BMI}$, mean (SD), $\mathrm{kg} / \mathrm{m}^{2}$ & $28.2(5.8)$ & $28.0(5.1)$ & $28.1(5.5)$ & 0.681 \\
\hline Overweight, n, (\%) & $178(33.8)$ & $226(42.3)$ & $404(38.1)$ & 0.104 \\
\hline Obesity, n, (\%) & $169(32.1)$ & $146(27.3)$ & $315(29.7)$ & 0.297 \\
\hline Waist circumference ${ }^{\star *}$, mean (SD), cm & $95.0(0.14)$ & $101.0(0.13)$ & $98.0(0.14)$ & $0.001^{*}$ \\
\hline SBP, mean (SD) mmHg & $126.4(18.8)$ & $134(19.2)$ & $130(19.3)$ & $0.000^{*}$ \\
\hline DBP, mean (SD) mmHg & $80.4(11.6)$ & $84(12.9)$ & $82.1(12.4)$ & $0.000 *$ \\
\hline Hypertension ${ }^{\mathrm{a}}, \mathrm{n},(\%)$ & $222(42.1)$ & $221(41.4)$ & $443(41.8)$ & 0.965 \\
\hline Diabetes $^{b}, \mathrm{n},(\%)$ & $82(15.6)$ & $73(13.8)$ & $155(14.6)$ & 0.662 \\
\hline Glycemia, mean (SD), mg/dL & $107(46.8)$ & $112(46.4)$ & $109.2(45.9)$ & 0.191 \\
\hline Smoking, n, (\%) & $104(19.7)$ & $131(24.5)$ & $235(22.1)$ & 0.066 \\
\hline Sedentary lifestyle, n, (\%) & $316(59.9)$ & $271(50.7)$ & $587(55.3)$ & $0.005^{\star}$ \\
\hline
\end{tabular}

Table 2. General cardiovascular risk profile according to the Framingham Risk Score (FRS) and Vascular Age (VA).

\begin{tabular}{|c|c|c|c|c|}
\hline Variable & $\begin{array}{c}\text { Women } \\
(n=495,49,3 \%)\end{array}$ & $\begin{array}{c}\text { Men } \\
(n=508,50,7 \%)\end{array}$ & $\begin{array}{c}\text { Total } \\
(\mathrm{n}=1003 ; 100 \%)\end{array}$ & $\mathrm{p}$-value \\
\hline FRS, mean (SD) & $11.8(0.1)$ & $24.7(0.2)$ & $18.3(0.2)$ & $0.000^{*}$ \\
\hline Low risk, n, (\%) & $248(24.7)$ & $98(9.8)$ & $346(34.5)$ & \\
\hline Moderate risk, $\mathrm{n},(\%)$ & $128(12.8)$ & $111(11.1)$ & $239(23.9)$ & \\
\hline High risk, $n,(\%)$ & $119(11.9)$ & $299(29.8)$ & $418(41.7)$ & \\
\hline $\mathrm{FRS}^{\star \star}$, by age, mean (SD) & & & & $0.001^{*}$ \\
\hline $20-39$ years & $3.1(0.1)$ & $3.9(0.0)$ & $3.5(0.1)$ & \\
\hline $40-59$ years & $9.7(0.1)$ & $18.6(0.1)$ & $14.1(0.1)$ & \\
\hline$\geq 60$ years & $21.4(0.1)$ & $40.7(0.2)$ & $31(0.2)$ & \\
\hline VA, mean (SD) & $61.6(20.8)$ & $66(17.7)$ & $63.8(19.5)$ & $0.000^{*}$ \\
\hline $20-39$ years & $30.3(13.6)$ & $35.2(10.4)$ & $32.7(12.6)$ & \\
\hline $40-59$ years & $62.3(14.9)$ & $63.2(13.2)$ & $62.7(14.1)$ & \\
\hline$\geq 60$ years & $78(10.1)$ & $79.4(7.8)$ & $78.8(8.9)$ & \\
\hline
\end{tabular}




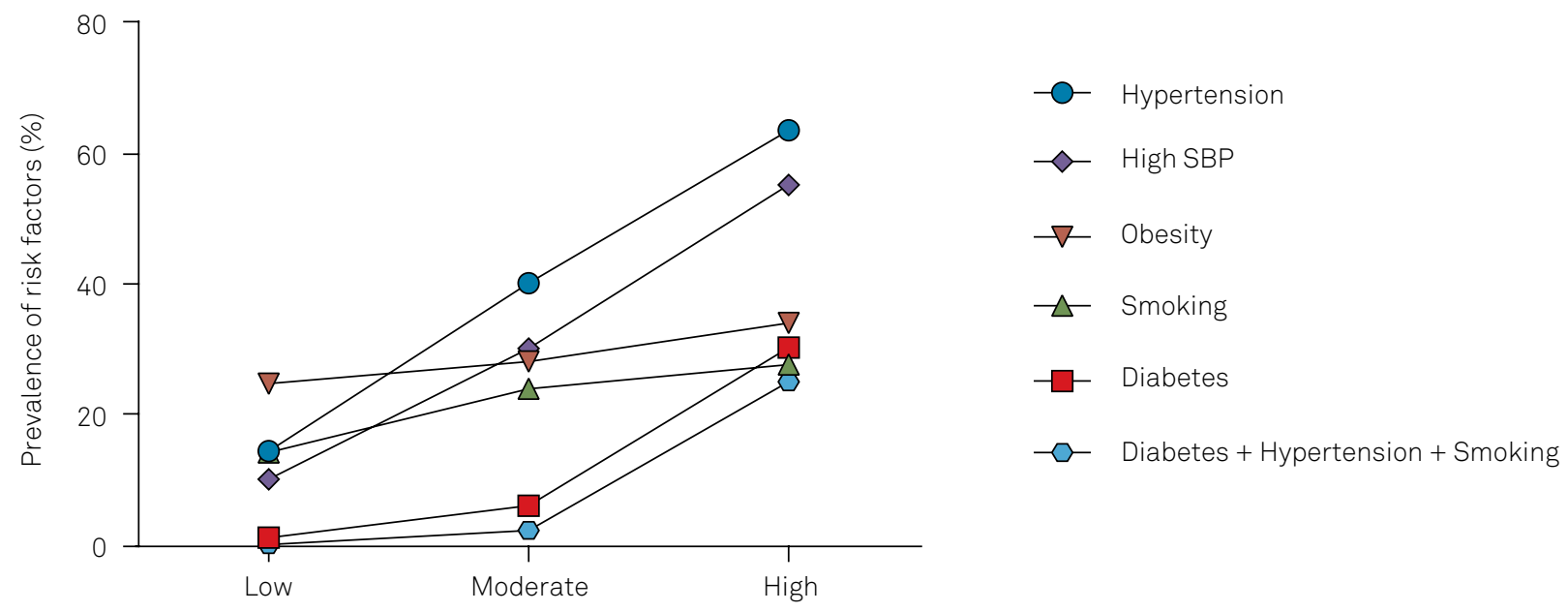

Figure. Prevalence of risk factors according to the Framingham Risk Score categories.

reported current treatment for diabetes and hypertension. In the group of women, $2 \%(\mathrm{n}=10)$ presented with hypertension and were smokers, whereas in the men's group, the presence of these two risk factors was $5 \%(\mathrm{n}=27)$. On average, $1 \%$ of the women $(n=5)$ and the men $(N=5)$ were diabetics and smokers; $8 \%$ of the women $(n=42)$ and as well as the men $(\mathrm{N}=43)$ presented with obesity and hypertension; $1 \%(n=5)$ of the individuals from both sexes had diabetes, hypertension and were smokers and $1 \%(n=5)$ of the women had diabetes, hypertension, obesity and were smokers, while the proportion of males $(n=1)$ with these four risk factors simultaneously was not significant.

\section{DISCUSSION}

We hypothesized that local traditions of our population, such as high consumption of saturated fats and sodium would be associated with higher levels of risk factors for cardiovascular diseases when compared with other studies performed in our country. Our hypothesis was not completely confirmed since the epidemiological profile of risk factors found was similar to that of the national studies.

However, most of the population-based surveys performed in Brazil until now used data from state capitals, which are the richest cities in the country and generally have higher levels of income and access to health ${ }^{15,16,17,18,19,20}$. Therefore, it is possible that some risk factors have a lower prevalence in most of the Brazilian cities than has been shown in the majority of the large national studies.

In a cross-sectional population-based study from 2008, carried out in a random sample of 1,968 participants, 20-69 years old, residing in the urban area of Pelotas, Rio Grande do Sul, the prevalence of obesity in the individuals aged 50-59 years was $22.9 \%$ in men and $31.4 \%$ in women, which was similar to the results of our study for this age group ${ }^{21}$.
In a study carried out through telephone interviews of residents of Brazilian capitals (Vigitel), the prevalence of obesity in men from 55-64 years was $19.9 \%$, whereas in women from the same age group it was $21.3 \%{ }^{16}$. Even though there may have been some limitations in the analysis of these data, as the prevalence of being overweight was based on selfreported information of height and weight given over the telephone, the prevalence of obesity, particularly in women, was higher in the state of Rio Grande do Sul compared to the national average ${ }^{16}$.

As stated by a national population-based home survey from 2008, conducted in households from urban and rural areas throughout Brazil, the national prevalence of being overweight in men of 50 years or older was of $38.2 \%$, and $32 \%$ for women of the same age. In the southern region, the prevalence of being overweight was $42.2 \%$ among men and $32.7 \%$ among women, which was similar to our study ${ }^{18}$.

As for diabetes, a telephone-based cross-sectional study conducted in 27 Brazilian state capitals in 2006 (Vigitel) found a self-reported diabetes rate of $12.5 \%$ in men from $55-64$ years of age and $18.2 \%$ in women of the same age ${ }^{19}$. According to an international study that analyzed data from health examination surveys and epidemiological studies corresponding to 370 country-years and 2.7 million participants in 2008, the prevalence of age-standardized diabetes was $9.8 \%$ in men and $9.2 \%$ in women. In our study, the prevalence of diabetes was similar to that of the regions with the highest levels of this disease in the world, such as Oceania (the prevalence of diabetes was $15.5 \%$ for men and $15.9 \%$ for women), USA and Spain. ${ }^{22}$

Regarding smoking, the National Health Survey in 2013, using data collected from 64,348 households, found a prevalence of $19 \%$ of smokers among individuals from 40-59 years ${ }^{23}$, which was similar to the results obtained from the national telephone-based survey from $2008^{15}$, where the rate of smoking between individuals from 45-54 years was $19.7 \%$. However, the prevalence of smoking was higher in men 
$(21.9 \%)$ than in women $(17.8 \%)^{15}$, a trend that was also seen in the present study, where $24.5 \%$ and $19.7 \%$ represented the rates of smoking among men and women, respectively.

As reported by a national telephone survey from 2009, the prevalence of hypertension in men from $45-54$ years was $30.5 \%$, while in women of the same age, it was $37.9 \%{ }^{24}$. In our study though, the prevalence of hypertension was $41.8 \%$, which was closer to the rate of $41.73 \%$ in individuals from 50-59 years found in a national survey conducted between 2002 and 2003 by the Ministry of Health, in which 9,211 residents from 16 Brazilian state capitals were included ${ }^{20}$. However, this might be explained by the older ages of the participants in our survey.

In the case of sedentary lifestyles, this study ${ }^{20}$ also found similar rates of inactivity to the present study, where a $41.73 \%$ of the individuals aged 50-59 years had a sedentary lifestyle. In a prospective cohort study from 2004 to 2005, which analyzed 4,297 people born in 1982 in the city of Pelotas, Rio Grande do Sul, women had a higher prevalence of sedentary lifestyle when compared to men ( $80.6 \%$ versus $49.2 \%)^{25}$. In our study, women were also significantly less active than men, but this difference was much less pronounced when compared with the cohort from Pelotas.

On average, the cardiovascular risk for women within 10 years was classified as moderate (11.8\%), and for men as high (24.7\%). Among the individuals with low cardiovascular risk, the majority were women $(24.7 \%)$, while $9.8 \%$ were men. In the high-risk classification, $29.8 \%$ were men and $11.9 \%$ were women. Cardiovascular risk and risk differences between the sexes increased progressively with age, as confirmed by the mean cardiovascular risk in men over 40 years being almost twice the value for women in the same age range.

The mean vascular age of the women was 61.6 years (6.9 years older than their chronological age), and in the men it was 66 years ( 8.9 years older than their chronological age). In a cross-sectional study that used the FRS based on laboratory data $^{26}$ to assess the cardiovascular risk profile of US residents of Latin American origin, 50.8\% of all women and $25.9 \%$ of men had a low cardiovascular risk. For moderate risk, 33.7\% of women and $28 \%$ of men were included in this category. Meanwhile, $46 \%$ of men and $15.6 \%$ of women had a high cardiovascular risk. The mean cardiovascular risk among women was $11.31 \%$ and among men, $18.74 \%$. This tendency of a higher FRS in men than in women, despite the distribution of the cardiovascular risk factors used in the calculation, was also verified in other studies ${ }^{27,28,29}$.

Concerning the limitations of this study, there are those intrinsic to cross-sectional studies, such as the fact that past exposures to risk factors were not evaluated, and possible errors of disease classification. However, according to Pereira et. al. ${ }^{20}$, taking into account the presence of a Brazilian health system with broad coverage such as the Unified Health System, it is likely that the information coming from the population is not far from reality ${ }^{20}$.

It should also be noted that a version of the risk score was used based on non-laboratory measures, which could have resulted in a lower accuracy in the estimation of cardiovascular risk. However, this resource has been used in many countries with low socioeconomic status, as laboratory tests are difficult to access, and the model allows the replacement of lipid tests by the BMI. Furthermore, since 2008, studies have shown that risk assessment methods based on non-laboratory measures are able to predict cardiovascular outcomes as effectively as methods using laboratory tests ${ }^{5}$.

Another limitation of the study was the use of selfreported information to assess the presence or absence of morbidities, and the convenience sampling, which could have selected individuals who were more motivated to seek health services.

As for the positive aspects, to the extent of the authors' knowledge, this is the first Brazilian study about stroke that evaluated the cardiovascular risk profile through the calculation of the vascular age. The results obtained will be used to improve the stroke campaigns in Santa Maria in the coming years.

In conclusion, the prevalence of risk factors for stroke in Santa Maria and the rates of individuals with moderate and high cardiovascular risk are alarming.

Thus, it is essential that proper attention should be given to the control of modifiable risk factors for cerebrovascular diseases at a local and national level.

\section{References}

1. Lozano R, Naghavi M, Foreman K, Lim S, Shibuya K, Aboyans V et al. Global and regional mortality from 235 causes of death for 20 age groups in 1990 and 2010: a systematic analysis for the Global Burden of Disease Study 2010. Lancet. 2012 Dec;380(9859):2095-128. https://doi.org/10.1016/S0140-6736(12)61728-0

2. Camargo EC, Bacheschi LA, Massaro AR. Stroke in Latin America. Neuroimaging Clin N Am. 2005 May;15(2):283-96. https://doi. org/10.1016/j.nic.2005.07.002

3. Muniz LC, Schneider BC, Silva IC, Matijasevich A, Santos IS. Accumulated behavioral risk factors for cardiovascular diseases in Southern Brazil. Rev Saude Publica. 2012;46(3):534-42. https://doi.org/10.1590/S0034-89102012005000021
4. Lavados PM, Hennis AJ, Fernandes JG, Medina MT, Legetic B, Hoppe A et al. Stroke epidemiology, prevention, and management strategies at a regional level: Latin America and the Caribbean. Lancet Neurol. 2007 Apr;6(4):362-72. https://doi.org/10.1016/S1474-4422(07)70003-0

5. Gaziano TA, Young CR, Fitzmaurice G, Atwood S, Gaziano JM. Laboratory-based versus non-laboratory-based method for assessment of cardiovascular disease risk: the NHANES I Follow-up Study cohort. Lancet. 2008 Mar;371(9616):923-31. https://doi.org/10.1016/S0140-6736(08)60418-3

6. D’Agostino RB, Vasan RS, Pencina MJ, Wolf PA, Cobain M, Massaro JM et al. General cardiovascular risk profile for use in primary care: the Framingham Heart Study. Circulation. 2008 Feb;117(6):743-53. https://doi.org/10.1161/CIRCULATIONAHA.107.699579 
7. Malachias MV, Gomes MA, Nobre F, Alessi A, Feitosa AD, Coelho EB. 7th Brazilian Guideline of Arterial Hypertension: Chapter 2 Diagnosis and Classification. Arq Bras Cardiol. 2016 Sep;107(3 Suppl 3):7-13. http://dx.doi.org/10.5935/abc.20160152

8. Sociedade Brasileira de Diabetes. Diretrizes da Sociedade Brasileira de Diabetes: 2015-2016. Rio de Janeiro: Sociedade Brasileira de Diabetes; 2016 [access 2016 Nov 11]. Available from: http://www.diabetes.org.br/sbdonline/images/docs/ DIRETRIZESSBD-2015-2016.pdf

9. Jensen MD, Ryan DH, Apovian CM, Ard JD, Comuzzie AG, Donato KA et al.; American College of Cardiology/American Heart Association Task Force on Practice Guidelines; Obesity Society. 2013 AHA/ACC/ TOS guideline for the management of overweight and obesity in adults: a report of the American College of Cardiology/American Heart Association Task Force on Practice Guidelines and The Obesity Society. Circulation. 2014 Jun;129(25 Suppl 2):S102-38. https://doi.org/10.1161/01.cir.0000437739.71477.ee

10. World Health Organization - WHO. Obesity: preventing and managing the global epidemic: report of a WHO consultation. Geneve: World Healt Organization; 2000. (WHO Technical Report Series, Vol. 894).

11. National Institutes of Health. Clinical guidelines on the identification, evaluation, and treatment of overweight and obesity in adults: the evidence report. Obes Res. 1998 Sep;6 Suppl S2:51S-209S.

12. Caspersen CJ, Pereira MA, Curran KM. Changes in physical activity patterns in the United States, by sex and crosssectional age. Med Sci Sports Exerc. 2000 Sep;32(9):1601-9. https://doi.org/10.1097/00005768-200009000-00013

13. Framingham Heart Study. Risk score calculators using BMI. (2016) [access 2016 Out 21]. Available from: http://www.framinghamheartstudy. org/risk-functions/cardiovascular-disease/10-year-risk.php\#

14. Faul F, Erdfelder E, Lang AG, Buchner A. G*Power 3: a flexible statistical power analysis program for the social, behavioral, and biomedical sciences. Behav Res Methods. 2007 May;39(2):175-91. https://doi.org/10.3758/BF03193146

15. Malta DC, Moura EC, Silva SA, Oliveira PP, Silva VL. Prevalence of smoking among adults residing in the Federal District of Brasilia and in the state capitals of Brazil, 2008. J Bras Pneumol. 2010;36(1):75-83. https://doi.org/10.1590/S1806-37132010000100013

16. Gigante DP, de França GV, Sardinha LM, Iser BP, Meléndez GV. Temporal variation in the prevalence of weight and obesity excess in adults: Brazil, 2006 to 2009. Rev Bras Epidemiol. 2011 Sep;14 Suppl 1:157-65. https://doi.org/10.1590/S1415-790X2011000500016

17. Schmidt MI, Duncan BB, Azevedo e Silva G, Menezes AM, Monteiro CA, Barreto SM et al. Chronic non-communicable diseases in Brazil: burden and current challenges. Lancet. 2011 Jun;377(9781):1949-61. https://doi.org/10.1016/S0140-6736(11)60135-9 P

18. Flor LS, Campos MR, Oliveira AF, Schramm JM. Diabetes burden in Brazil: fraction attributable to overweight, obesity, and excess weight. Rev Saude Publica. 2015;49:29. https://doi.org/10.1590/S0034-8910.2015049005571
19. Schmidt MI, Duncan BB, Hoffmann JF, Moura L, Malta DC, Carvalho RM. Prevalence of diabetes and hypertension based on self-reported morbidity survey, Brazil, 2006. Rev Saude Publica. 2009 Nov;43 Suppl 2:74-82. https://doi.org/10.1590/S0034-89102009000900010

20. Pereira JC, Barreto SM, Passos VM. [Cardiovascular risk profile and health self-evaluation in Brazil: a population-based study]. Rev Panam Salud Publica. 2009 Jun;25(6):491-8. Portuguese. https://doi.org/10.1590/S1020-49892009000600004

21. Gigante DP, Dias-da-Costa JS, Olinto MT, Menezes AM, Silvia M. [Adult obesity in Pelotas, Rio Grande do Sul, Brazil, and the association with socioeconomic status]. Cad Saude Publica. 2006 Sep;22(9):1873-9. Portuguese. https://doi.org/10.1590/S0102-311X2006000900018

22. Danaei G, Finucane MM, Lu Y, Singh GM, Cowan MJ, Paciorek CJ et al.; Global Burden of Metabolic Risk Factors of Chronic Diseases Collaborating Group (Blood Glucose). National, regional, and global trends in fasting plasma glucose and diabetes prevalence since 1980: systematic analysis of health examination surveys and epidemiological studies with 370 country-years and 2.7 million participants. Lancet. $2011 \mathrm{Jul}$;378(9785):31-40. https://doi.org/10.1016/S0140-6736(11)60679-X

23. Malta DC, Andrade SSCA, Stopa SR, Pereira CA, Szwarcwald CL, Silva Júnior JD et al. Brazilian lifestyles: National Health Survey results, 2013. Epidemiol Serv Saude. 2015;24(2):217-26. https://doi.org/10.5123/S1679-49742015000200004

24. Iser BP, Claro RM, Moura EC, Malta DC, Morais Neto OL. Risk and protection factors for chronic non communicable diseases by telephone survey - Vigitel Brazil - 2009. Rev Bras Epidemiol. 2011;14 suppl 1:90-102. https://doi.org/10.1590/S1415-790X2011000500010

25. Azevedo MR, Horta BL, Gigante DP, Victora CG, Barros FC. Factors associated to leisure-time sedentary lifestyle in adults of 1982 birth cohort, Pelotas, Southern Brazil. Rev Saude Publica. 2008;42 suppl 2:70-7. https://doi.org/10.1590/S0034-89102008000900010

26. Cohn T, Miller A, Fogg L, Braun LT, Coke L. Impact of individual and neighborhood factors on cardiovascular risk in white hispanic and nonDhispanic women and men. Res Nurs Health. 2017;40(2):120-31. https://doi.org/10.1002/nur.21778

27. Jousilahti P, Vartiainen E, Tuomilehto J, Puska P. Sex, age, cardiovascular risk factors, and coronary heart disease: a prospective follow-up study of 14786 middle-aged men and women in Finland. Circulation. 1999 Mar;99(9):1165-72. https://doi.org/10.1161/01.CIR.99.9.1165

28. Wilson PW, Castelli WP, Kannel WB. Coronary risk prediction in adults (the Framingham Heart Study). Am J Cardiol. 1987;59(14):G91-4. https://doi.org/10.1016/0002-9149(87)90165-2

29. Tunstall-Pedoe H, Kuulasmaa K, Mähönen M, Tolonen H, Ruokokoski E. Contribution of trends in survival and coronar y-event rates to changes in coronary heart disease mortality: 10-year results from 37 WHO MONICA Project populations. Lancet. 1999;353(9164):1547-57. https://doi.org/10.1016/S0140-6736(99)04021-0 